\title{
THE PUN-GROUP OF LINGUISTIC DEVICES IN ADVERTISING MEDIA DISCOURSE
}

\author{
Hamlet Arakelyan* \\ Yerevan State University
}

The language of advertising is unique and very peculiar in comparison with other properties of media discourse. The effectiveness of speech in advertising media discourse focuses on attracting the target audience. Since the language of advertising is characterized by distinguished persuasive function, the creators of ads spare no effort to make them catchy, interesting and witty. This is the reason why various linguistic devices are used to facilitate the comprehension and memorization of advertisements. In this regard, a significant role is performed by wordplay, as the intentional usage of puns ensures the effectiveness of the composed texts.

Keywords: advertising media discourse, linguistic devices, speech impact, wordplay, punnical devices.

\section{Introduction}

The aim of the present article is to study the pun-devices used in English advertisments which is accomplished through the application of the methods of observation, description and investigation of the linguostylistic features of linguistic elements. The effectiveness of advertising discourse relies heavily on the content and arrangement of the linguistic means appearing in ads. It is for this very reason that advertising media discourse actively "indulges in code play" (Cook, 1992, p. 277).

It should be acknowledged that pun and humour influence the target audience positively by creating favourable associations about the advertised product. Research has shown that humour found in ads captures the attention of consumers, creates interest, which in its turn influences the 
positive choices regarding the advertised service (Gibson, 2019). Humour also facilitates understanding of an advertisement, and grasp always creates positive emotions (Weinberger, Gulas, 1992). It should be noted that the part of our consciousness which focuses the attention on this or that object has a very complex neuropsychological structure but it is almost always conditioned by the past experiences of a person. It mostly functions with the help of emotional and instinctive responses (Du Plessis, 2005). As the main aim of an advertisement is to attract attention, it "has to be designed to attract an emotional response from us" (Du Plessis, 2005, p. 107).

\section{The pun-group of linguistic devices in advertisements}

The pun-group of linguistic devices used in advertising media discourse is regarded as very effective in the light of the impact achieved in speech. This does not come as a surprise, as wordplay influences the target audience with various means of verbal wit. Nowadays puns are so extensively used in advertising texts that almost every ad has at least a touch of wordplay in it. Being a witty play of polysemic words' shades of meanings, a pun catches the attention of the buyer by creating comical and funny contexts. Wordplay transforms a banal advertisement into an attractive and humourous text which in its turn awakens the associative memory of the buyers and affects their behavioural choices (Goddard 1998; Leech 1966). Here are some examples of pun in ads:

What to expect when you're expecting. (AdoptUSKids, 2019)

We get rid of $99 \%$ of dirt, but not of your dirty ex boyfriend. (Dk12 soap, 2019)

Plastic tock tick tock. (Iceland, 2018)

The last of the adduced examples underlines the importance of plastic disposal which appears as a choice of the current product, but it also prompts the buyer to do the same. By means of the wordplay the marketers give the potential buyers a hint that the time of plastic is slowly expiring. 
The use of puns in ads is motivated by the idea of making the verbal presentation of the product interesting by means of non-standard expressions which are more effective when it comes to attracting the attention of the potential consumers. However, it is important to mention that the degree of effectiveness of the ad is reliant on the language fluency level of the target audience. For consumers with a lower level of language fluency advertisements including puns are not effectual as the comprehension of the latter demands proficient skills of communication and understanding. On the other hand, to fully understand a wordplay, and fix its meaning in mind, the consumer has to make a huge mental effort. The latter is also conditioned by the fact that a potential buyer starts to analyze the polysemy of the pun which can be used for the purpose of creating interest or humour (Dyer, 1988).

It should be acknowledged that it is thanks to linguistic puns used in advertisements that unique neologisms emerge. This enhances not only the development of advertising discourse but also the vocabulary of a certain language. Thus, it does not come as a surprise that a paradoxical, semasiologically non-normative lexical unit like smileage appears in an ad:

Our trucks get more smileage. Help us feed NYC.

(CityHarvest, 2018)

The mentioned neologism is formed of the words smile and mileage. The idea is that the drivers of the company pass hundreds of kilometers every day to collect food from philanthropists in order to distribute it to the people in need. Accordingly, their miles give people smiles; hence the word smileage.

The neologism bluetiful is created by the same logic. The words blueberry and beautiful are partially combined by the authors of the ad to create associations connected with the company name and objectives which revolve around blueberries:

Positively healthy. Positively delicious. Positively

bluetiful. (U.S. Highbush Blueberry, 2019) 
According to L.V. Zhilina's research, the ads selling health and beauty products and food "have the biggest tendency to utilize neologisms" (Zhilina, 2016, p. 34). Neologisms, including puns, appear in advertising to name the novelties created by modern entrepreneurs. The appearance of electric cars on the international market caused the emergence of various neologisms and advertising agencies spared no effort to create new catchy linguistic expressions for novel extra-linguistic objects. Most of these linguistic units are formed by wordplay:

WattCar? Got questions about owning an electric car?

Get the answers at GoUltraLow.com. (GoUltraLow, 2018)

In the example mentioned above, the neologism wattcar has been used to name the electric car. Apparently, the use of the question mark creates a unique wordplay as the words watt and what are homophones in the English language. The question mark following the neologism proves that the wordplay has been used on purpose. Back in 2018, not a lot of information could be found about electromobiles. This is why the neologism WattCar? which is based on the homophonic features of watt and what and involves a play upon these elements, could be rephrased to 'What car? (Wattcar)'.

The following neologism presents another case formed by a wordplay based on one of the elements in the expression:

There's a feeling you get when you talk face-to-face, not face-to-website. (Mutual of America, 2019)

Face-to-website depicts the digital culture which has become an integral part of the modern-day society. Digital communication performs the role of a substitute for the natural, human contact. The ad adduced above underlines the importance of face-to-face communication and a personal approach against the new conventional ways of conducting all the activities online.

To summarize, the frequent use of pun-neologisms in English advertising media discourse is due to the fact that a rich content is supposed to be expressed through a concise structure, and pun is the wittiest among the linguistic devices that facilitate memorization, though the comprehension of a pun requires an extra effort from the consumers. The same can be ascribed to linguistic paradox, which appears when two 
opposite notions are brought together to create a new meaning. If an advertising text involves a linguistic paradox, it usually contradicts itself, thus catching the attention of the target audience. It is both true and false at the same time, and that is illustrated in the following example:

The world's best radiologist isn't a radiologist yet.

The qure.ai solution detects abnormalities in head CT scans in seconds and brings the most critical cases to the immediate attention of a radiologist. (Fractal, 2019)

The first line of the ad immediately gives food for thought with the help of a linguistic paradox. The rest of the text which is the actual advertisement has nothing to do with the first line. This comes to prove that advertisers frequently utilize linguistic devices to influence consumers and to make sure they 'continue reading' to get to the core ad message. Here's another example of an ad with a linguistic paradox that illustrates this point:

The only downside to three more flavors of left twix is three more flavors of right twix. (Twix, 2019)

Anyone who has ever tried Twix knows that both bars of the chocolate have the same taste, but this ad contradicts itself by showing it as a 'downside' in the beginning. When the potential buyers read the first part of the ad, they don't know that a linguistic paradox is waiting on the other side, so they read on in order to understand what is bad about three more flavours. The unexpected appearance of the paradox makes them think, and if they are fast to comprehend, they enjoy the wittiness of the text which enhances the verbal impact.

The ads below created by loan agencies are perfect examples of attention grabbers by means of negative connotations that make the target audience read on:

The neighbour's dog.

It barks.

Day and night.

It barks when you walk into your house. 
When you leave your house.

It barks at the wind. It barks at the rain.

Bark. Bark. Bark.

Never stops.

The solution?

Learn to speak dog.

Let him know how you feel.

That's the only option.

Isn't it?

Or you could talk us about a home mover mortgage instead. (Yorkshire Building Society, 2018)

So your neighbour loves to party 24/7.

With lots of friends.

He loves life.

A lot.

What should you do about it?

Embrace it.

Stop being such a stick in the mud.

You're only middle-aged once.

Live a little.

Or don't.

And talk to us about a home mover mortgage instead. (Yorkshire Building Society, 2018)

These creative ads remind of unique examples of Japanese Hokus, where parts of a text usually have nothing to do with each other, but create a common meaning on the whole.

Among the pun devices there are such uses of lexical oppositions in which an advertised object appears in a positive context in contrast to an antonym. For example, in the Coca-Cola ad presented below, the popular drink appears in contrast with a man's tiredness by using the antonymous pair on and off. This ad is targeted at the youth to make them drink coke when they feel tired or dizzy: 
When you're off, a Coca-Cola is right on. (Coca-Cola, 2019)

The ads below have also been created by linguistic opposition:

More Science. Less Fear. (MSK Cancer Center, 2018)

Januvia works when my blood sugar is HIGH, and works less when my blood sugar is LOW. For adults with Type 2 Diabetes. (Merck, 2018)

One Big Mac. Two new sizes. (McDonalds, 2018)

The English advertising media discourse is full of diverse uses of antithesis. The latter is a literary device in which an opposition or contrast of ideas is expressed. It mostly relies on contextual opposition as in the following example:

I am spiritually awake. But I'd like to be physically asleep. (Yogi, 2018)

\section{Other effective means of phrasing advertisements}

Irony is another pun-device in which the way of phrasing the ad is meant to convey the opposite meaning of what is expressed, thus making advertising texts humorous and witty. A unique example of irony use is the ad of the online MA course of the University of Liverpool:

Set an example to the kids. Spend more time online. Get a master's degree online from a Russell Group University. (University of Liverpool, 2018)

Usually it is the adults who set an example for the kids by spending less time online and by reducing their screen time as much as possible. The first part of the ad makes one read on to understand how spending more time 
online can be beneficial for kids. The use of irony in this case makes the ad memorable and more effective.

Irony can also come along with the help of a rhetorical question which entails no answer. In the examples below, for instance, the potential answer is supposed to be ironic too:

DO YOU WANNA BE FAMOUS... by wasting food?

1.3 tons of food goes to trash every year. Avoid waste.

DO YOU WANNA BE FAMOUS... by wasting paper?

Each person consumes the equivalent to one eucalyptus tree per year in paper manufacturing industry. Avoid waste.

DO YOU WANNA BE FAMOUS... by polluting with kitchen oil?

The frying oil can pollute up to 25 thousand liters of water. Do properly dispose.

DO YOU WANNA BE FAMOUS... by wasting water?

It's recommended the consumption of until 100 liters of water per person per day. Avoid waste. (Avenida Shopping Center, 2019)

The first question (do you wanna be famous) appears in the media text in big and bold letters, while the second part which contains irony is typed in small and almost invisible font size. It is interesting to notice that these commercial ads cover vast social considerations. There is a tendency to use social ads which usually carry important messages as means of attracting attention and creating positive associations about a commercial product.

It should be mentioned that if the target audience is familiar with the metaphors or cliches used in a given advertisement, the effectiveness of the latter is higher as the utilization of familiar expressions facilitates comprehension and memorization. What is more, it creates positive associations with the product, of course if the chosen linguistic devices lack negative connotation. People also tend to remember and reiterate advertising 
texts with well-known expressions more frequently. This is why the use of popular expressions, idioms or famous quotes is really beneficial when it comes to verbal impact. These quotations may appear in advertisements both partially and wholly. Sometimes advertisers might rephrase parts of a famous expression to deliver their message accordingly. In these cases we deal with contextual and partial quotations which usually have the characteristic features of a pun as in the following examples:

Finding the happy in every ending. A Netflix original series. Unbreakable Kimmy Schmidt. (Netflix, 2019)

Yes, the Sun will rise in the morning. Here's something equally certain. With our high-yield savings promotion, HSBC offers certainty on the horizon. Earn $1.30 \%$ APY. (HSBC, 2018)

If life is but a dream, this is living. (Kiawah Island Real Estate, 2018)

In Gold We Trust. (Gold Eagle, 2018)

In the last example, there is a hidden quotation instead of a direct citation. The authors of the advertisement have very successfully used the famous expression 'In God We Trust' and changed it with wordplay. In this case, Gold substitutes God to meet the needs of the commercial campaign.

Fast. Not Furious. (Virgin Media, 2018)

The quotation in this ad directly relates to the title of the popular movie 'Fast and Furious'. With a bit of a wordplay, it creates the expected associations. Another interesting example of pun-quotations is the following ad:

BFF: Bottomless Fries Forever. (Red Robin, 2019)

This fast food company has used the famous abbreviation BFF (Best Friends Forever) and changed its meaning in favour of the advertisement. 
With the help of an indirect impact achieved by this use of the abbreviation, advertisers make the potential buyers associate the fries that are sold with the concept of best friends, which in its turn brings about positive and pleasant emotions.

Another instance of a pun-quotation is the following example where the famous expression 'until death do us apart' is used to illustrate the longevity of the advertised furniture which outlives its owner:

Until death do us apart. (Vepsäläinen furniture, 2019)

\section{Conclusion}

The investigation allows to conclude that the linguistic devices used in advertising discourse as means of verbal impact, not only shape and make the ads comprehensive, but also facilitate the impact with the help of a distinctive content, structure and frequency of use. Particularly for this reason the pun-devices used in English media discourse are of utmost importance as they create positive associations regarding the advertised product and make ads memorable, thus enhancing their effectiveness in terms of verbal impact.

\section{References}

Cook, G. (1992). The discourse of advertising. London: Routledge and Kegan Paul.

Du Plessis, E. (2005). The advertised mind: Ground-breaking insights into how our brains respond to advertising. London \& Sterling, VA: Millward Brown \& Kogan Page.

Dyer, G. (1988). Advertising as communication. London \& New York: Routledge.

Gibson, J.M. (2019). An introduction to the psychology of humor. Abingdon $\&$ New York: Routledge.

Goddard, A. (1998). The language of advertising. London \& New York: Routledge.

Leech, G.N. (1966). English in advertising: A linguistic study of advertising in Great Britain. London: Longman. 
Weinberger, M.G., \& Gulas, C.S. (1992). The impact of humor in advertising: A review. Journal of Advertising, 21 (4), 35-59. https://doi.org/10.1080/00913367.1992.10673384

Zhilina, L.V. (2016). Advertising as a neologism-oriented discourse: A study of advertising English and German languages. Kultura Mira, 6. Retrieved from http://etnosocium.ru/zhurnal-kultura-mira-\%E2\%84\%966-2016).

\section{Sources of Data}

Avenida Shopping Center. (2019). Retrieved 13.11.19 from https://www.adsoftheworld.com/media/print/avenida_center_famous

Coca-Cola. (2019). Retrieved 09.06.19 from https://www.bestadsontv.com/ad/105261/ Coca-Cola-First-Date

Dk12 soap. (2019). Retrieved 13.11 .19 from https://www.adsoftheworld.com/media/print/dk12_the_most_realistic_soap_on_the_market

Red Robin. (2019). Retrieved 21.07.19 from https://www.adsoftheworld.com/media/ integrated/red_robin_all_the_fulls

Vepsäläinen furniture. (2019). Retrieved 13.11.19 from https://www.adsoftheworld.com/media/print/vepsalainen_until_death_do_us_part)

\section{Other Sources of Data}

AdoptUSKids. (2019, January 14). Bloomberg Businessweek.

City Harvest. (2018, January 13). The Wall Street Journal.

Fractal. (2019, May 4-10). The Economist.

GoUltraLow. (2018, February 04). The Observer.

Gold Eagle. (2018, January 09). The Wall Street Journal.

Gold Eagle. (2018, July 13). The Wall Street Journal.

HSBS. (2018, January 19). The Wall Street Journal.

Iceland.(2018, January 20). The Daily Mirror.

McDonalds. (2018, March 01). The Daily Mirror.

MSK Cancer Center. (2018, December 10). The New Yorker.

Merck. (2018, December 24\&31). The New Yorker.

Mutual of America (2019, May 27). Bloomberg Businessweek.

Netflix. (2019, January 28). The New Yorker.

Twix. (2019, May 28). Good Housekeeping. 
U.S. Highbush Blueberry. (2019, June 17). Bloomberg Businessweek.

University of Liverpool. (2018, March 11). The Observer.

Virgin Media. (2018, March 12). The Daily Mirror.

Yorkshire Building Society. (2018, May 13). The Observer.

Yorkshire Building Society. (2018, June 24). The Observer.

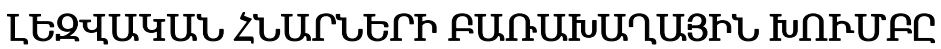

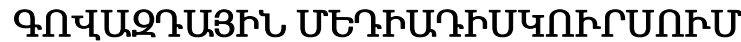

\section{Zuufitin Unuptijuiq}

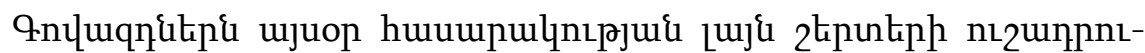

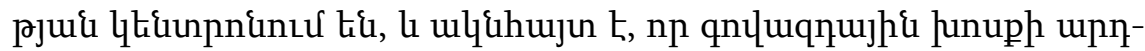

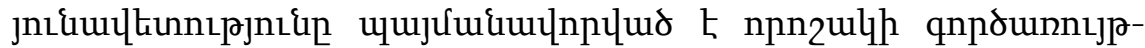

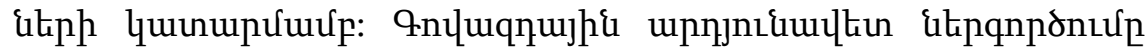

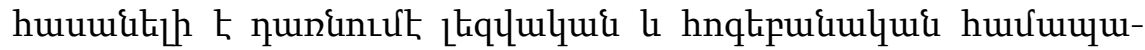

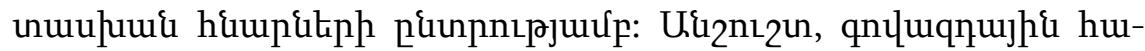

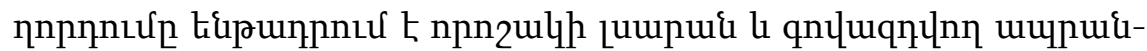

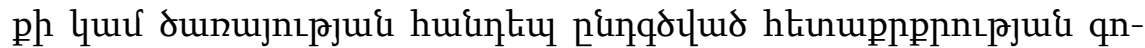

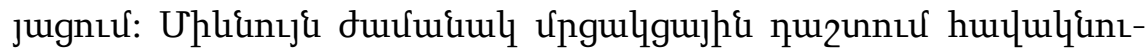

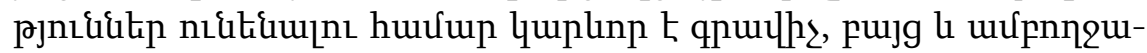

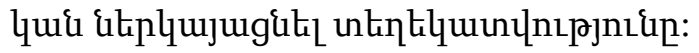

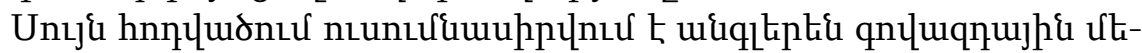

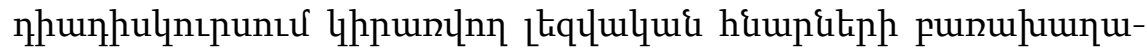

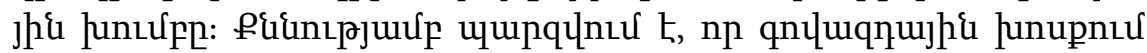

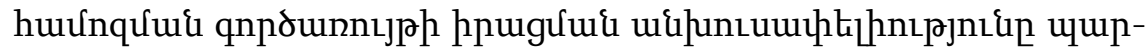

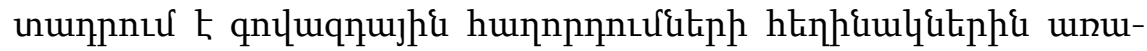

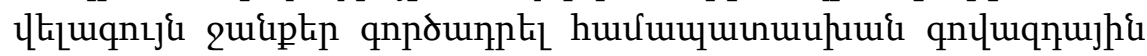

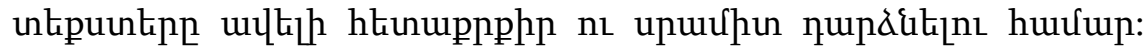

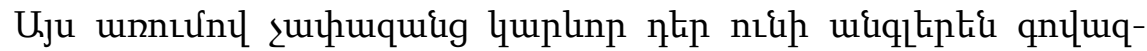

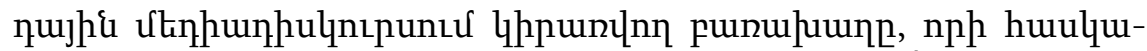

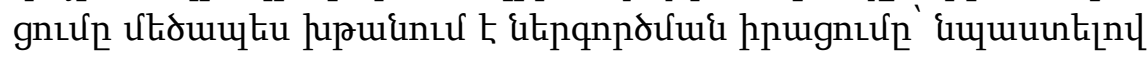

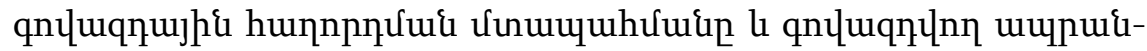

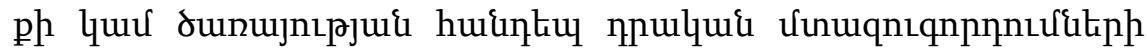
d̀uuunnưuin:

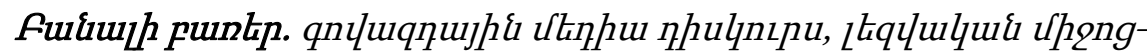

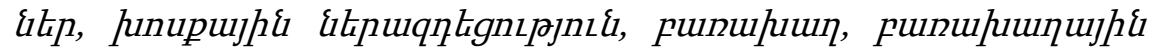
hulph hiupintip: 